\title{
O Desenvolvimento Econômico e a Retomada da Abordagem Clássica do Excedente
}

\author{
Economic development and the resumption \\ of the classical approach to surplus
}

FRANKLIN SERRANO*,**

CARLOS MEDEIROS****

RESUMO: Neste artigo mostramos como um arcabouço analítico baseado na abordagem do superávit clássico pode ser utilizado para a compreensão de algumas questões centrais do desenvolvimento econômico das nações e da economia brasileira nas últimas décadas, em particular. Começamos a discutir as deficiências da abordagem tradicional da economia do desenvolvimento e a incapacidade da abordagem neoclássica para explicar alguns dos fatos estilizados mais importantes do processo de desenvolvimento. Mostramos como o esquema proposto pode explicar esses fatos e, nessa perspectiva, quais são as restrições internas e externas ao desenvolvimento econômico. Por fim, ilustramos nosso argumento com um breve resumo de nossa pesquisa sobre o desenvolvimento recente da economia brasileira. PALAVRAS-CHAVE: Excedente; desenvolvimento; investimento; consumo.

ABSTRACT: In this article we show how an analytical framework based on the classical surplus approach can be used to the understanding of some central matters of the economic development of the nations and of the Brazilian economy in the last decades, in particular. We start discussing the shortcomings of the traditional approach to development economics and the inability of the neoclassical approach to explain some of the more important stylized facts of the development process. We show how the scheme proposed can explain these facts and, in this perspective, what are the internal and external constraints to economic development. Finally, we illustrate our argument with a brief summary of our research on the recent development of the Brazilian economy.

KEYWORDS: Surplus; development; investment; consumption.

JEL Classification: O11.

\footnotetext{
* Professor adjunto e pesquisador do grupo de pesquisa em economia política do Instituto de Economia da Universidade Federal do Rio de Janeiro - UFRJ, Rio de Janeiro/RJ, Brasil. E-mail: Franklin.s@openlink.com.br.

* Serrano agradece o apoio financeiro do CNPq, e ambos agradecem a crítica de um parecerista anônimo dessa revista.

$* * *$ Professor adjunto e pesquisador do grupo de pesquisa em economia política do Instituto de Economia da Universidade Federal do Rio de Janeiro - UFRJ, Rio de Janeiro/RJ, Brasil. E-mail: ca29@ centroin.com.br.
} 


\section{INTRODUÇÃO}

Neste artigo apresentamos resumidamente a forma como a economia do desenvolvimento econômico vem sendo reconsiderada em nosso próprio programa de pesquisa e prática de ensino (tanto para a graduação quanto para a pós-graduação), no grupo de pesquisa em economia política do Instituto de Economia da Universidade Federal do Rio de Janeiro. ${ }^{1}$ Por esse motivo a maioria das referências aqui é a nossos próprios trabalhos. ${ }^{2}$ Ao longo dos últimos anos temos repensado a economia do desenvolvimento adotando o "ponto de vista" da abordagem clássica do excedente, em sua forma mais moderna reformulada por Piero Sraffa e Pierangelo Garegnani, desde os primeiros anos da década de $60 .{ }^{3}$ Esse evidentemente não é o caminho que está na moda atualmente e, até onde sabemos, não é adotado em nenhum outro lugar da América Latina.

Na próxima seção (II) discutimos duas limitações importantes da tradição da economia do desenvolvimento tal como esta se afirmou no pós-guerra. A seguir (seção III) apresentamos brevemente a abordagem clássica do excedente e ilustramos sua relevância para a questão do desenvolvimento a partir da discussão de dois importantes fatos estilizados do processo de desenvolvimento econômico, a saber, i) a queda da proporção da força de trabalho empregada na agricultura (seção IV) e ii) a conexão entre taxa de investimento e taxa de crescimento do produto a longo prazo (seção V). Na seção VI discutimos a relação entre as restrições internas e externas ao crescimento econômico em nosso esquema de análise. A seção VII ilustra o esquema proposto apresentando um resumo de nossa análise sobre o desenvolvimento recente da economia brasileira. A seção VIII contém observações finais.

\section{DOIS PROBLEMAS DA ECONOMIA DO DESENVOLVIMENTO TRADICIONAL ${ }^{4}$}

A economia do desenvolvimento tradicional, apesar de seus grandes méritos, tinha duas sérias limitações. Em primeiro lugar, os economistas do desenvolvimen-

\footnotetext{
${ }^{1}$ O grupo conta com a participação, além dos autores desse trabalho, dos professores José Luis Fiori (coordenador), Fábio Freitas, Sergio Cesaratto (da Universidade de Siena, Itália) e do pesquisador Carlos Pinkusfeld Bastos.

${ }^{2}$ Muitos desses documentos estão disponíveis em versões preliminares na nossa homepage em www. redeal.org (procurem por programas e então "workshop 2000" e então "teoria do desenvolvimento econômico - Carlos Medeiros \& Franklin Serrano”).

${ }^{3}$ Ver Garegnani (1987), Ciccone(1998).

${ }^{4}$ Por economia do desenvolvimento tradicional referimo-nos à ampla literatura desenvolvida entre os anos 40 e 70, dirigida à promoção da industrialização em áreas atrasadas. Para uma recente e competente resenha ver Chakravarty (1997).
} 
to tinham uma tendência crônica de partir muito depressa para uma dimensão normativa, sugerindo intervenções de política pública, sem esclarecer suficientemente bem como economias em desenvolvimento de fato funcionavam. Essa tendência era tão forte que, freqüentemente, alguns dos melhores economistas do desenvolvimento tratavam as economias capitalistas em desenvolvimento como se fossem sistemas planificados ou socialistas.

Como um exemplo claro dessa tendência temos o fato de que mesmo Kalecki ignorava o problema da demanda efetiva nas economias que ele chamava de "mistas" na suposição otimista de que o governo dessas economias determinava como quisesse o nível de investimento da economia. Outro exemplo do mesmo tipo é o uso difundido da arbitrária "Lei de Say" na literatura estruturalista latino-americana (e que até hoje sobrevive nos argumentos sobre "hiato de poupança" de Cepal e demais ditos "neo-estruturalistas"). Segundo essa "Lei" qualquer redução no consumo automaticamente aumenta o nível de investimento a longo prazo, o que evidentemente só seria possível numa economia centralmente (bem) planejada (ver seção VI, adiante). ${ }^{5}$

A outra deficiência básica da economia do desenvolvimento, muito relacionado à anterior, foi o fato de que, em geral, economistas do desenvolvimento não se dedicaram a uma discussão detalhada da operação normal do mecanismo de mercado, do que este podia ou não realisticamente fazer. Isso levou freqüentemente a um certo menosprezo das dificuldades de planejamento nos mercados de produto e, mais importante ainda, a uma grande ambigüidade sobre o que acontece nos mercados dos assim chamados fatores de produção (isto é, como a distribuição, o emprego do trabalho e a utilização do capital são realmente determinados em economias capitalistas). Por exemplo, um grande número de economistas do desenvolvimento com perfil mais crítico argumentavam (e ainda argumentam) que as ineficiências da alocação "estática" de recursos de várias intervenções, por meio de políticas de desenvolvimento, eram mais do que compensadas pelos efeitos positivos de eficiência "dinâmica". Mas o que será que eles queriam dizer por ineficiência da alocação estática de recursos? Será que eles queriam dizer que economias em desenvolvimento teriam, na ausência de intervenções, uma tendência espontânea para um equilíbrio geral estático Pareto-eficiente com pleno emprego de todos os fatores? Provavelmente não. Entretanto, se não era o conceito neoclássico de eficiência, o que economistas do desenvolvimento realmente queriam dizer com eficiência (ou ineficiência) de alocação estática? ${ }^{6}$ Será que mercados competitivos desregulados realmente podem gerar alocações eficientes, tendência ao pleno em-

\footnotetext{
${ }^{5}$ Uma crítica a essa visão da relação entre consumo e investimento no pensamento desenvolvimentista se encontra em Serrano (2001a).

${ }^{6}$ A mesma ambigüidade aparece em qualquer outro problema que exija uma discussão de preços relativos. Por exemplo, quando economistas do desenvolvimento discutem a questão das vantagens comparativas no comércio internacional, nunca fica claro se eles se referem à visão neoclássica "Heschker-OhlinSamuelson” ou à visão clássica de, por exemplo, Ricardo, que, ao contrário do que está na maioria dos livros-texto, era totalmente diferente (não supunha, por exemplo, o pleno emprego).
} 
prego de todos os fatores de produção, equilíbrio automático no comércio exterior e na balança de pagamento? Estas são questões gerais muito controversas, porém cruciais em economia. Economistas do desenvolvimento ficavam freqüentemente satisfeitos em supor que mercados competitivos de produto, e especialmente de fatores, funcionavam bem no Norte, mas por algum motivo não existiram (ou não funcionariam) no Sul.

Dada tal atitude "imperfeccionista", muito difundida, mas teoricamente problemática, não foi difícil para a contra-revolução neoliberal-neoclássica posteriormente convencer boa parte dos praticantes da disciplina que o problema do desenvolvimento era justamente o de criar os mercados (e instituições associadas) que, supostamente, funcionaram tão bem no Norte e estavam de algum modo faltando nas áreas mais tropicais. ${ }^{7}$

Foi essa contra-revolução, evidentemente, que levou a economia do desenvolvimento para a atual posição muito estreita e bastante limitada, em que os defensores de políticas de desenvolvimento ativistas ficam restritos a tentar provar que, no Sul, as "falhas de mercado" são maiores que as "falhas de governo" e, desse modo, a intervenção é Pareto-superior. ${ }^{8}$

Essa atitude defensiva, porém, não parece ser necessária. Em nossa visão, a descrição neoclássica da operação dos mecanismos de mercado é errada tanto para o Norte quanto para o Sul, por um número grande e bem documentado de razões teóricas, empíricas e históricas. O fato de a economia neoclássica ser, hoje em dia, ideológica e culturalmente dominante não significa necessariamente que esteja cientificamente correta.

Se olharmos para a experiência recente do Norte (desemprego em massa) e do Sul (baixo crescimento da renda per capita e conseqüente ampliação das diferenças de riqueza entre as nações) nas últimas duas décadas, parece bastante clara a necessidade urgente, do ponto de vista político, de estados de bem-estar keynesianos no Norte e de estados desenvolvimentistas no Sul. Parece, no entanto, ser bastante difícil que essa luta possa ser intelectualmente sustentada se a economia do desenvolvimento permanecer presa nesse estreito limite teórico.

Acreditamos, dessa forma, haver um problema econômico básico na discussão do desenvolvimento. Esse problema não se esgota com uma necessária ampliação da agenda do desenvolvimento econômico para incluir movimentos sociais, políticas sociais, questões de gênero, aspectos ambientais e assim por diante. Porém, se quase todos os envolvidos na discussão (até os que não são economistas) implicitamente aceitam o dogma neoclássico de que uma economia capitalista competiti-

\footnotetext{
${ }^{7}$ Note que algo análogo aconteceu na economia keynesiana no Norte, quando o meio termo teórico instável entre as novas idéias de Keynes (como a demanda efetiva e sobre a determinação institucional da taxa de juros monetária) e suas visões neoclássicas antigas (sobre a produtividade marginal dos fatores e a oferta e demanda por moeda) não sobreviveram ao monetarismo e ao ataque das expectativas racionais, na então prevalecente "síntese neoclássica" (Serrano, 2001b).

${ }^{8}$ Essa parece ser a postura típica de autores atualmente em grande destaque como Krugman (1992), Rodrik(1997) ou Stiglitz (1989).
} 
va, por si só, em princípio, geraria uma alocação ótima de recursos “escassos”, é muito difícil avançar na maioria dessas questões mais complexas. É a adoção explícita ou implícita da visão neoclássica do mecanismo de mercado que torna populares proposições vagas e arbitrárias (com freqüencia puramente imaginárias), como, por exemplo, o trade off entre eqüidade e eficiência ou a suposição de que quase todos os impostos e o salário mínimo são distorcionários, entre outros. $\mathrm{Na}$ verdade essas proposições se seguem dos dois teoremas fundamentais de economia do bem-estar neoclássica e só têm relevância prática se existe uma tendência forte ao equilíbrio de pleno emprego. ${ }^{9}$

O desafio principal para a economia do desenvolvimento é então entender melhor como as economias capitalistas do Norte e do Sul realmente funcionam. Isso exige alguns estudos teóricos e uma enorme quantidade de trabalhos aplicados para nos livrarmos dos mitos da economia neoclássica e da consideração, totalmente distorcida, da evolução das economias do Norte e do Sul, como a retratada pelo FMI, Banco Mundial e instituições acadêmicas do mainstream ao longo das últimas duas décadas.

\section{A RETOMADA DA ABORDAGEM CLÁSSICA DO EXCEDENTE}

Em um sentido muito amplo, se consideramos as teorias econômicas do funcionamento geral dos mecanismos de mercado, podemos dizer que a maior parte delas é baseada em três grandes idéias ou princípios gerais, que no passado teriam sido chamados de "princípios de economia política" (ou mais recentemente de “economia").

O primeiro destes é o conceito do excedente econômico, típico dos antigoseconomistas clássicos incluindo desde Petty até Ricardo (e retomado mais tarde por Marx quando a economia já começava a seguir o caminho que foi dar na abordagem neoclássica). De acordo com esse princípio, o excedente é determinado pelas condições técnicas de produção e um salário usual de "subsistência". ${ }^{10}$ A competição opera distribuindo o excedente entre os vários tipos de rendas da propriedade por meio do sistema de preços. ${ }^{11}$ Essa noção do excedente é evidentemente compatível com várias teorias diferentes e modelos específicos e tem sido utilizada como

\footnotetext{
${ }^{9}$ Para um exemplo de análise que pressupõe a validade das proposições neoclássicas, ver os trabalhosde Amartya Sen (1981).

${ }^{10}$ Note que, como Sraffa ressaltou, as condições salariais modernas, além do "elemento de subsistência sempre presente”, também podem ser vistas como algo que absorve parte do excedente, via barganha. Sraffa discutiu, e seus seguidores têm discutido, o possível papel da interação entre mudanças nos salários nominais e a política de taxa de juros de longo prazo do Estado como influenciando a determinação dessa parte "excedente" do salário (ver Serrano, 1993 e Pivetti, 1991).

${ }^{11}$ Ver Freitas e Serrano (1998).
} 
um esquema analítico geral por vários autores, explicita ou implicitamente (mesmo que estes não se considerem como seguidores dos clássicos). ${ }^{12}$

O segundo é o assim chamado princípio da substituição (ver Serrano, 2001b), que ocasionou a revolução marginalista e o nascimento da abordagem neoclássica. $\mathrm{Na}$ verdade, é a noção de substituição (tanto direta quanto indireta) de fator que dá a base para a idéia de que existe uma relação geral inversa entre o preço e a quantidade utilizada de um fator. Essa relação inversa é condição necessária para ser possível dizer que os preços dos fatores refletem a "escassez relativa" das dotações dos fatores de produção. A escassez dos fatores (particularmente a de trabalho) é a única base necessária, em economias em que existe produção, para o argumento de que os preços relativos dos produtos são índices de escassez, e tudo mais que se segue a partir disso, inclusive os principais teoremas da teoria Heshcker-OhlinSamuelson do comércio internacional.

A abordagem neoclássica evoluiu tanto, e em tantas direções, que se tornou realidade muito diferente e distante de sua origem. Entretanto, não obstante o alargamento do seu escopo e das suas aplicações, é fundamental reconhecer que o funcionamento do mecanismo de mercado permanece sendo completamente baseado na suposta operação desse princípio fundamental da substituição, ${ }^{13}$ tanto quanto a abordagem clássica é baseada na noção do excedente.

Existe ainda um terceiro princípio fundamental, o princípio de demanda efetiva. De acordo com esse princípio, o nível agregado do produto (e não somente dos produtos relativos) é determinado pela demanda monetária daqueles que podem pagar os preços de oferta normais. Esse princípio foi introduzido por Keynes (e por Kalecki) nos anos 30 e é também uma dessas grandes idéias que levaram a vários desenvolvimentos diferentes em muitas áreas e permitiu a produção de muitas teorias e modelos específicos organizados ao seu redor.

Os primeiros dois princípios (excedente e substituição) permitiram, naturalmente, o desenvolvimento de duas abordagens distintas para a teoria econômica geral e, particularmente, para a teoria dos preços e da distribuição, respectivamente a clássica e a neoclássica. O terceiro princípio (demanda efetiva), relacionado a perguntas talvez menos gerais e não necessariamente ligadas a uma abordagem particular da teoria do preço (e da distribuição), não poderia, e realmente não gerou, a elaboração de uma outra abordagem geral para a economia. É então natural que a maior parte das discussões fundamentais sobre o princípio de demanda efetiva tenha estado, de uma forma ou de outra, relacionada a sua compatibilidade ou incompatibilidade com essas abordagens mais gerais baseadas nos outros dois princípios. ${ }^{14}$

\footnotetext{
12 Alguns exemplos de teorias que usam o princípio do excedente de algum modo, sem serem teorias explicitamente clássicas, são a análise de Lewis da economia dual, a economia de insumo-produto de Leontief e os modelos de inflação de conflito distributivo, entre muitos outros.

${ }^{13}$ Ver Serrano (2003).

${ }^{14}$ Um exemplo é o debate mencionado na nota 7 , relacionando o princípio de demanda efetiva à teoria neoclássica baseada na substituição do fator. Outros exemplos são as controvérsias acerca da assim
} 
Com essa simples taxinomia, é bastante fácil explicar a essência do projeto geral da moderna abordagem clássica do excedente liderada por Piero Sraffa em Cambridge, Reino Unido, e desenvolvida por seus seguidores mais próximos. Esse projeto pode ser convenientemente resumido aqui como sendo baseado em três pontos.

O primeiro ponto é a crítica interna ao princípio da substituição evidenciando que este não pode ser deduzido em economias que usam meios de produção produzidos. É uma crítica interna da tentativa de tratar o capital como um fator de produção da mesma maneira que um fator não reprodutível, como o trabalho e a terra, o que mostra que existem sérias falhas teóricas na idéia de que os preços dos fatores possam refletir a "escassez relativa". Essa crítica é muito importante, pois mostra que não há fundamento teórico sólido nem para a tendência ao pleno emprego dos fatores nem para os teoremas tradicionais da teoria do comércio internacional citada acima. ${ }^{15}$

O segundo ponto é a defesa a um retorno na teoria geral do valor e da distribuição para uma visão baseada no conceito do excedente, base para uma teoria "objetiva" dos preços relativos, em que preços competitivos reflitam as condições técnicas de produção e os mecanismos de distribuição de renda.

Finalmente, uma vez que estamos retornando aos clássicos depois de Keynes, o terceiro ponto é que devemos integrar na análise o princípio de demanda efetiva. Isto é, é importante buscar uma ponte entre as teorias keynesiana-kaleckiana e a clássica. Isso nos permite estudar a importância da demanda efetiva não só para as flutuações de curto prazo, mas também para o processo de acumulação de longo prazo. Assim, como veremos a partir da seção VI, normalmente é a demanda efetiva que determina a produção, mesmo a longo prazo, e sua expansão é necessária para o crescimento do investimento e da capacidade produtiva.

\section{O EXCEDENTE E O DESENVOLVIMENTO ECONÔMICO}

A descrição acima pode soar bastante abstrata, mas pensamos que essa abordagem não só é teoricamente muito mais consistente que a abordagem neoclássica, como também, e mais importante ainda para nossos propósitos aqui, provê uma base muito melhor para explicar os fatos estilizados do desenvolvimento econômico.

Podemos ilustrar aqui o que foi dito mencionando, para sermos breves, apenas dois (embora muito importantes) desses fatos estilizados: i) a conexão entre desenvolvimento econômico e a queda da participação do emprego na agricultura e ii) a

chamada teoria de Cambridge da distribuição apresentada por Kaldor, Joan Robinson e outros, em que é questionado se essa teoria seria o melhor caminho para assegurar a compatibilidade entre o princípio do excedente e o princípio de demanda efetiva (para uma avaliação negativa sob um ponto de vista sraffiano, ver Serrano, 1996 e 2001a).

${ }^{15}$ Para um resumo da crítica sraffiana à teoria neoclássica do comércio internacional e referências, ver Steedman (1987). 
associação entre a taxa do investimento e a taxa de crescimento (tanto em termos absolutos quanto por trabalhador).

O primeiro desses fatos estilizados pode ser visto como o resultado de duastendências estruturais importantes. A primeira é um aumento inicial da produtividade na agricultura, sem o qual não pode haver mesmo nenhum excedente. ${ }^{16} \mathrm{~A}$ segunda é a mudança inevitável na estrutura da demanda, diminuindo o papel da agricultura, assim que a divisão social do trabalho, que se torna factível justamente por esse aumento da produtividade nos setores básicos, fica cada vez mais complexa (isso é o que está por trás das curvas de Engel). Essa era, evidentemente, a visão dos antigos economistas clássicos, fortemente preocupados com esse processo de mudança estrutural e com a escolha de políticas e instituições que o acelerasse, nas circunstâncias históricas e geográficas específicas. William Petty, por exemplo, defendia investimentos públicos em infra-estrutura para baixar o custo dos alimentos; Cantillon estava preocupado com a melhoria da qualidade das manufaturas urbanas de forma que essas pudessem ser trocadas por uma parte do excedente agrícola, necessária para alimentar os moradores da cidade; os fisiocratas franceses enfatizavam a necessidade de usar bens de capital modernos para "industrializar" a agricultura; Ricardo acreditava que a Inglaterra devia importar comida de países onde terras de boa qualidade fossem mais abundantes, para baixar o custo dos alimentos. ${ }^{17}$

Nas trajetórias de desenvolvimento do pós-guerra podemos ver a enorme importância desse padrão de mudança estrutural. Um bom exemplo foram as dificuldades das estratégias de desenvolvimento e industrialização em aumentar o salário real e os padrões de vida, na América Latina e na Índia, onde a agricultura não se modernizava no ritmo adequado. Outros exemplos notáveis foram as dificuldades crônicas sofridas na União Soviética ou as mudanças dramáticas na China, nas últimas décadas, quando a agricultura se modernizou. ${ }^{18}$

\section{RETORNOS MARGINAIS DECRESCENTES PARA A ACUMULAÇÃO DE CAPITAL E “CONVERGÊNCIA”"19}

O segundo fato estilizado, mencionado acima, a existência de uma forte cone-xão entre a taxa de investimento em capital e a taxa de crescimento do produto e do produto por trabalhador, mostra que, na experiência histórica real, não existe

\footnotetext{
${ }^{16}$ Sobre o papel fundamental do excedente em alimentos na história econômica, ver Medeiros (2001a).

${ }^{17}$ Ver Aspromourgos (1996).

18 Sobre a experiência chinesa, ver Medeiros (1999). Sobre a experiência brasileira, ver a penúltima seção deste artigo. Para uma análise da importância do rápido crescimento da produtividade na agricultura para o desenvolvimento do consumo de massa nos Estados Unidos, ver Medeiros (2000).

${ }^{19}$ Os argumentos formais que fundamentam esta seção se encontram em Cesaratto e Serrano (2002).
} 
nenhuma tendência geral para a convergência e que países que aceleram a acumulação de capital (físico), de fato, crescem permanentemente muito mais rápido.

Como é bem conhecido, esse fato estilizado é difícil de ser explicado por meio da teoria neoclássica do crescimento exógeno usual (Solow), em que acumulação de capital tem retornos marginais decrescentes. De fato, na última década, aproximadamente, um enorme esforço foi posto na chamada teoria neoclássica de crescimento endógeno, para tentar explicar a falta de evidência empírica dos retornos marginais decrescentes para a acumulação de capital. Esses modelos de crescimento endógeno são, no entanto, baseados em suposições extremamente arbitrárias sobre as relações tecnológicas da economia.

Devemos notar que a tendência para os retornos marginais decrescentes da acumulação de capital na teoria do crescimento exógeno é, de fato, uma conseqüência da teoria neoclássica de preços e da distribuição, uma vez que nessa teoria existe o mecanismo de market clearing nos mercados dos fatores de produção.

Os retornos decrescentes da acumulação de capital não são, assim, uma hipótese tecnológica, mas um resultado inevitável de supor que os bens de capital adicionais vão ser combinados com uma força de trabalho plenamente empregada.

A literatura neoclássica do crescimento endógeno, por outro lado, só consegue eliminar a tendência para retornos decrescentes da acumulação de capital recorrendo a suposições fantásticas sobre "externalidades", que sempre têm a forma adequada e a magnitude precisa para compensar exatamente a tendência básica para retornos decrescentes, que vêm da força de trabalho supostamente escassa. ${ }^{20}$

É bastante irônico ver tantos economistas desenvolvimentistas adotando a teoria neoclássica do crescimento endógeno e suas suposições extremamente ad hoc, aparentemente sem perceber o quão estapafúrdio é uma teoria do crescimento, supostamente aplicável a economias em desenvolvimento, ser baseada na idéia de que a força de trabalho é um fator escasso.

Parece claro, porém, ou pelo menos sempre pareceu claro tanto para os antigos economistas clássicos quanto para a tradicional literatura do desenvolvimento econômico, que economias capitalistas em geral, e economias em desenvolvimento em particular, tinham excedente estrutural de mão-de-obra. De uma perspectiva clássica, a força de trabalho em economias em desenvolvimento é qualquer coisa, exceto escassa (e também nas economias desenvolvidas, o tamanho da força de trabalho historicamente parece nunca ter sido um obstáculo importante ao crescimento de longo prazo).

Meramente retirando a idéia neoclássica de escassez de trabalho imediatamente eliminamos a tendência para os retornos decrescentes da acumulação de capital, já que os bens de capital adicionados serão normalmente combinados com mais trabalho (ou trabalhadores mais produtivos). Desse modo, em uma visão clássica

\footnotetext{
${ }^{20}$ Existem, é claro, alguns modelos de crescimento endógeno em que existe desemprego, mas este é, por hipótese, causado por salários reais rígidos dada a suposição (que hoje graças a Sraffa sabemos ser incorreta) de que a substituição dos fatores sempre funciona.
} 
do crescimento, a capacidade produtiva da economia depende diretamente da taxa de acumulação do capital. Se simplesmente adicionamos as considerações smithianas sobre retornos crescentes de escala (que foi mais tarde retomada por Kaldor) ${ }^{21}$ podemos também facilmente explicar a conexão entre a acumulação e o crescimento do produto por trabalhador.

É importante ter em vista que, se o crescimento de longo prazo depende diretamente da acumulação de capital, não existe absolutamente nenhuma razão para esperar uma convergência automática de taxas de crescimento, já que os resultados da convergência são inteiramente baseados na tendência neoclássica tradicional para retornos marginais decrescentes do capital. ${ }^{22}$ Então, uma vez que a idéia implausível de escassez do trabalho é removida, fica claro que o desenvolvimento desigual é simplesmente a norma em economias capitalistas. Isso também significa que algum tipo de Estado Desenvolvimentista que esteja preocupado em promover a acumulação de capital é uma condição realmente necessária (embora não suficiente) para o "catch-up" ou a "convergência".

\section{RESTRIÇÕES INTERNAS E EXTERNAS À ACUMULAÇÃO DE CAPITAL E DESENVOLVIMENTO}

Um leitor atento poderia a esta altura observar que a abordagem tradicional para a economia do desenvolvimento sempre esteve de uma maneira ou de outra implicitamente baseada na noção de excedente. ${ }^{23}$ Particularmente autores como Prebisch (1949) e Furtado, os líderes do pensamento desenvolvimentista da Cepal sempre enfatizaram esse conceito. Furtado, em particular, dá um papel central a esse conceito em diversas de suas obras a partir dos anos 60 (Furtado, 1967, 1972 e 1992). Prebisch também passou a se centrar cada vez mais explicitamente na questão do excedente em seus últimos trabalhos (por exemplo, Prebisch, 1981).

Onde estaria então a novidade do esquema aqui proposto?

Os pioneiros da Cepal de fato utilizaram o conceito do excedente como elemento central em suas análises. No entanto, a forma como o utilizaram continha algumas sérias limitações, que precisam ser superadas.

A primeira é que, ao contrário do que diziam os economistas clássicos discu-

\footnotetext{
${ }^{21}$ Ver, entre outros, Kaldor (1996).

${ }^{22}$ Note que, como Sraffa mostrou, toda a idéia do produto marginal do capital de qualquer maneira só faria sentido no contexto restritivo de um modelo com capital homogêneo. Nenhuma referência a esses resultados críticos dos primeiros anos da década de 60 pode ser achada nos livros-texto da moderna teoria de crescimento. Não existe também nenhuma referência aos trabalhos mais recentes de Garegnani (2000), Schefold (2000) e Petri (1999) que mostram que os problemas teóricos do capital, discutidos por Sraffa, são endêmicos a todas as versões da teoria do equilíbrio geral neoclássico, e não somente um "problema de agregação" limitado a um modelo de função de produção "ingênua". A literatura crítica produzida depois de meados dos anos 70 foi simplesmente ignorada (ver Serrano (2001b, 2003).

${ }^{23}$ Agradecemos a um parecerista anônimo da REP por levantar essa importante questão.
} 
tidos na seção IV, a discussão cepalina sobre a questão da disponibilidade de alimentos se centrava não tanto na produtividade e custos da agricultura atrasada quanto, de forma pouco consistente teoricamente com o conceito clássico de excedente que enfatiza os custos de reprodução da economia, sobre uma suposta inelasticidade física da oferta de alimentos, que por sua vez era resultado da estrutura fundiária arcaica da América Latina. Seria essa suposta inelasticidade "malthusiana" da oferta agrícola que causaria a chamada inflação estrutural e agravaria os conflitos distributivos associados ao desenvolvimento. ${ }^{24}$

Historicamente, ao contrário das previsões cepalinas, na América Latina a oferta agrícola aumentou bastante, particularmente no Brasil, seguindo o crescimento da economia. Não houve escassez física de alimentos, mas mesmo assim o alto custo de produção dos alimentos resultante de deficiências estruturais na infra-estrutura de transporte e comercialização e do baixo crescimento da produtividade da agricultura foi (no caso do Brasil, até os anos 80, ver seção VII a seguir) de fato um fator importante de pressão inflacionária e acirramento do conflito distributivo. Assim, apesar de os cepalinos serem supostamente baseados na noção de excedente clássica, sua análise da agricultura latino-americana parece não ter sido suficientemente consistente com esse conceito, e uma análise mais consistente com o conceito de excedente nos parece explicar melhor a experiência histórica da América Latina.

Por outro lado, é inegável que os pioneiros da Cepal, como Prebisch e Furtado, foram bem mais consistentes em seu uso do conceito de excedente quando discutiram não as condições de produção do excedente, mas sim os seus usos (ou condições de realização).

Os pioneiros da Cepal não achavam que o excedente em nossas economias era baixo por conta da baixa produtividade dos setores básicos. Pelo contrário, achavam que nas economias latino-americanas a parcela dos lucros já era elevada. A principal restrição interna à acumulação era, segundo esses autores, que uma parcela grande demais desse excedente era gasta no consumo de luxo ou supérfluo das classes dominantes locais, o que faria sobrar pouco para o investimento.

O problema com essas análises é o uso constante por esses autores da chamada "Lei de Say", que postula, mas não explica por que nem como, que "a oferta cria sua própria procura" e que, portanto, subtraindo o consumo agregado dos dois termos da frase anterior, "a poupança determina o investimento".

Essa visão teve (e ainda tem) forte influência na economia do desenvolvimento. Prebisch (1949, pp. 76-77) em seu manifesto estruturalista, logo depois de afirmar a necessidade de um aumento na acumulação de capital e dizer que para isso "[...] não parece indispensável refrear o consumo das grandes massas, que em geral é extremamente baixo", argumenta que "[...] a formação de capital tem que lutar contra uma tendência muito acentuada a certas modalidades de consumo, que

24 O "modelo" de inflação estrutural cepalino era caracterizado por uma "curva de oferta" de alimentos vertical (ver Bastos, 2001). 
muitas vezes se mostram incompatíveis com um grau elevado de capitalização" e que o esforço de acelerar a acumulação "[...] em geral não se compatibiliza com o tipo de consumo de alguns setores da coletividade".

Prebisch insiste que esse consumo excessivo de "alguns setores da coletividade" (gasto improdutivo em nosso esquema) "é uma manifestação do conflito latente entre o propósito de assimilar às pressas certos estilos de vida que os países de técnica mais avançada foram alcançando progressivamente, graças ao aumento de sua produtividade, a as exigências de uma capitalização sem a qual não nos será possível conseguir um aumento semelhante" ${ }^{25}$

Prebisch, portanto, vê o consumo das elites como redutor da poupança e a partir daí do investimento e do crescimento a longo prazo da capacidade produtiva nas economias latino-americanas. De forma mais geral, a crítica ao consumo de luxo das elites e a idéia de falta de poupança como principal restrição interna ao crescimento sempre foram a visão dominante (mas não unânime) na Cepal. Celso Furtado teve importante papel no desenvolvimento e difusão desse ponto de vista. Para Furtado "[...] na medida em que o consumo da minoria de altas rendas deve acompanhar a evolução do consumo dos grupos de rendas médias e altas de países muito mais ricos - processo que é facilitado pela posição dominante das firmas internacionais na introdução de novos produtos e na direção da propaganda — os limitados recursos disponíveis para investimento tenderão a ser absorvidos na diversificação do consumo da referida minoria, em prejuízo do referido processo de difusão. Em conseqüência, a aceleração do crescimento do consumo dos grupos de altas rendas terá como contrapartida a agravação do subdesenvolvimento, na medida em que este significa disparidade entre os níveis de consumo de grupos significativos da população de um país” (1972, p. 31). ${ }^{26}$

A grande vantagem de seguirmos a visão da abordagem clássica do excedente na forma retomada por Sraffa é que esta nos permite por um lado seguir com mais coerência o conceito de excedente clássico onde ele é mais útil (na questão da importância da produtividade dos setores produtores de bens-salários para a produção do excedente potencial) e ao mesmo tempo não cair na armadilha teórica da "Lei de Say", isto é, simplesmente não é verdade que todo o excedente potencial não consumido será investido como queriam Prebisch e Furtado. ${ }^{27}$

Nas economias capitalistas em desenvolvimento, isto é, aquelas que, de uma forma ou de outra (como os cepalinos admitiam que era o caso da América Latina),

\footnotetext{
${ }^{25}$ Note que aqui Prebisch está associando a acumulação ao aumento do produto por trabalhador numa linha clássica como em Adam Smith.

${ }^{26}$ Ver também Furtado (1992) e os comentários de Bielschowsky (2000, pp. 32-33 e nota 12). Note que para Furtado (1992) a desaceleração da acumulação causada pelo consumo de luxo das elites tinha indiretamente conseqüências distributivas, pois fazia a economia subdesenvolvida crescer mais lentamente e perpetuava, assim, sua situação de excedente de mão-de-obra, o que enfraquecia o poder de barganha dos trabalhadores e dificultava o aumento dos salários reais e da participação dos salários na renda, tendência esta que teria ocorrido nos países centrais.

${ }^{27}$ Para uma crítica mais detalhada ao uso da "Lei de Say" pelos pioneiros da Cepal, ver Serrano (2001a).
} 
são capazes de produzir um excedente significativo acima dos padrões de subsistência usuais, a produção é normalmente limitada pelo nível de demanda efetiva. Isso ocorre tanto a curto quanto especialmente a longo prazo (já que se torna mais fácil adaptar o produto à demanda, com o passar do tempo). Isso significa que a longo prazo, pela operação do princípio da demanda efetiva, as decisões de investir geram poupança agregada por variações da renda e do produto. A acumulação do capital depende, desse modo, não das decisões de poupar, mas do crescimento do investimento. ${ }^{28}$

Porém, a expansão contínua de investimento que gera capacidade produtiva para o setor privado depende, em última instância, do nível e da taxa do crescimento da demanda final (gastos do governo, consumo e exportações) pelo efeito do acelerador (ou ajuste do estoque de capital).

Em nossa visão é esse efeito supermultiplicador (isto é, os efeitos combinados do acelerador e do multiplicador) que explica os fatos estilizados conectando a taxa de investimento e a taxa de crescimento.

Os dados sobre o crescimento econômico no longo prazo parecem mostrar que, de fato, é a taxa do investimento que se ajusta à taxa de crescimento, depois de um intervalo de tempo considerável..$^{29}$ Isso pode ser explicado, em um regime de crescimento liderado pela demanda, pelo fato de que, quando a taxa de crescimento da demanda final aumenta, o investimento e a capacidade produtiva começam a crescer juntos. Inicialmente não ocorre um aumento da taxa de investimento, uma vez que um aumento no grau de utilização efetivo da capacidade pode acomodar, e de fato acomoda, a expansão mais rápida tanto da demanda final quanto do investimento. ${ }^{30}$ Apenas gradualmente, durante um período mais longo de tempo, por um "acelerador flexível”, a taxa do investimento começa a aumentar para ajustar mais adequadamente os níveis de capacidade produtiva ao nível e à taxa de crescimento da demanda final. ${ }^{31} \mathrm{Em}$ todo caso, o ritmo de crescimento liderado pela demanda é fortemente afetado por políticas macroeconômicas de cada Estado. Essas políticas são no longo prazo muito influenciadas, com a possível exceção do país que emite a moeda corrente internacional, pela necessidade de satisfazer a restrição externa ou de balança de pagamento.

Desse modo, a chave para entender o processo de acumulação de capital nos países em desenvolvimento é o estudo da complexa interação, em cada período histórico, entre o comércio internacional e o ambiente financeiro econômico, a situação geopolítica associada (que é crucial para entender o acesso aos mercados

\footnotetext{
${ }^{28}$ Para uma crítica ao hiato de poupança no modelo de dois hiatos de Chenery, ver Serrano e Willcox (2000).

${ }^{29}$ Ver Blomstrom, M. et al. (1996).

${ }^{30}$ Ver Serrano (2000).

31 Note, porém, que isso é normalmente alcançado meramente pelo crescimento mais rápido do investimento do que da demanda, durante um certo período de tempo, e não por uma redução absoluta da demanda final. Sobre o supermultiplicador, ver Serrano (1995, 1996 e 2001a), Serrano e Willcox (2000) e Cesaratto, Serrano e Stirati (2003).
} 
e finanças) e as políticas de desenvolvimento de cada Estado nacional. Diferentes tentativas de Estados desenvolvimentistas de acelerar a mudança estrutural, melhorando a infra-estrutura, expandindo e diversificando o mercado interno, ou, alternativamente, de conquistar posições estratégicas em mercados de exportação, terão graus completamente diferentes de sucesso de acordo com o ambiente internacional no qual estejam inseridas. Nossa pesquisa em desenvolvimento enfoca justamente o estudo da interação de mudanças no ambiente internacional econômico e geopolítico, sob diferentes sistemas financeiros e monetários internacionais, e as mudanças nas políticas e nos resultados de desenvolvimento de diferentes Estados. O canal de transmissão principal entre esses dois níveis são as mudanças na situação de balança de pagamento dos Estados em desenvolvimento, que por sua vez afetam diretamente as políticas macroeconômicas e, por meio delas, o ritmo de acumulação de capital. ${ }^{32}$

Temos usado, já por algum tempo, esse esqueleto geral como a base para um programa de pesquisa. Esse programa já produziu vários estudos específicos sobre o crescimento de países ou regiões específicas e consideramos que os resultados são encorajadores. ${ }^{33}$ Esse esquema não só é teoricamente consistente como também nos permite escapar de ambas as armadilhas: da visão "fatalista" em que o ambiente internacional determina exaustivamente as possibilidades nacionais de desenvolvimento (como muita da literatura marxista sobre globalização, por exemplo) e também do "nacionalismo metodológico", às vezes excessivo (em que tudo é creditado às políticas ou instituições nacionais específicas, desconsiderando os elementos externos), hoje em dia comuns na maioria da literatura do desenvolvimento mais crítica. ${ }^{34}$

\section{REPENSANDO O DESENVOLVIMENTO BRASILEIRO À LUZ DA ABORDAGEM DO EXCEDENTE}

Tendo em vista essa releitura crítica do pensamento desenvolvimentista e, em particular, o latino-americano e brasileiro, busca-se nesta seção descrever brevemente como temos tentado reinterpretar a experiência brasileira nas últimas décadas..$^{35}$

\footnotetext{
${ }^{32}$ Veja em particular Medeiros e Serrano (1999), em que a estrutura interpretativa histórica geral é desenvolvida.

${ }^{33}$ Medeiros (1997) provê uma comparação entre as experiências do leste asiático e latino-americano nos anos 90. Medeiros (1998) discute a crise asiática e a situação da Coréia do Sul. O caso da China é discutido em Medeiros (1999). O caso brasileiro será visto na próxima seção.

${ }^{34}$ Um bom exemplo dessa abordagem é a análise de Amsden sobre a Coréia.

35 O Brasil nos anos 90 é analisado em Serrano (1998) e Medeiros e Serrano (2001b); a questão da relação entre o crescimento das exportações e o desenvolvimento e o papel de exportações na experiência pós-guerra brasileira são discutidos em Medeiros e Serrano (2001a); o papel da expansão dos gastos “improdutivos" e da expansão dos mercados como principal estímulo ao investimento privado é analisado em Serrano (2001a); a questão da aceleração da inflação e sua estabilização a longo prazo é
} 
Como vimos acima, essa abordagem rompe completamente com a velha ortodoxia econômica neoclássica que hoje está por trás do chamado pensamento neoliberal. Os trabalhos teóricos dessa abordagem têm demonstrado repetidamente que as economias de mercado, mesmo quando estes são "perfeitos" e "completos", não têm necessariamente uma tendência espontânea ao pleno emprego da força de trabalho nem à plena utilização do capital já existente, o que, aliás, também é fartamente comprovado pela evidência empírica.

Uma economia capitalista tende a produzir, não tudo o que seria possível, mas aquilo que se pode vender a preços que satisfaçam os requisitos mínimos de rentabilidade privada, o que Keynes chamava de "demanda efetiva".

Como os "fatores de produção" (trabalho e capital) não são escassos, seus "preços" (salários, taxa de lucro) não são índices de sua "escassez" intrínseca e se formam por meio de um processo de barganha, muito influenciado por relações de poder. A distribuição de renda é resultante desse processo complexo em que interagem os determinantes dos salários nominais (organização sindical, padrões de consumo mínimos socialmente toleráveis etc.), a evolução da produtividade e a política econômica do Estado, particularmente no que diz respeito à taxa de juros e à taxa de câmbio.

No caso do Brasil nossa análise parte do problema da inflação e estabilização. Nesse caso, a interrupção dos fluxos de capitais externos na década de 80 e a crise da dívida externa da "década perdida" é que explicam, em grande parte, o fracasso dos diversos planos de estabilização que tentavam desindexar a economia. A necessidade de manter a taxa de câmbio real, para produzir um superávit na conta corrente para honrar o serviço da dívida, levava à indexação do câmbio em prazos cada vez mais curtos e esta, por sua vez, tornava necessária a indexação dos juros, para evitar a fuga de capitais, com a indexação salarial em geral vindo mais defasada.

O retorno dos fluxos de capitais externos no início dos anos 90 foi o que tornou sustentável a estabilização do câmbio nominal e a desindexação dos juros e dos salários no Plano Real (que, aliás, era muito pouco diferente dos demais planos "heterodoxos" anteriores) e reduziu a inflação permanentemente (ver Serrano (1998) e Medeiros e Serrano(2001b) e Bastos (2001)).

Os efeitos distributivos de tais políticas e a relação mais geral entre distribuição e distintos padrões de crescimento são discutidos em Medeiros (2001b). Neste caso, ao contrário do que muitos "pobrólogos" da moda afirmam atualmente, argumenta-se que o crescimento econômico persistente tem forte efeito de redução da pobreza. O padrão concentrador de renda do período de alto crescimento da economia brasileira até o início da década de 80 foi produzido por uma série de fatores específicos, a saber: baixo crescimento da produtividade e evolução desfavorável do preço relativo dos alimentos, perda de poder de compra do salário mí-

vista em Bastos (2001) e, finalmente, a conexão entre crescimento econômico, distribuição de renda e pobreza, em Medeiros (2001b). 
nimo, forte repressão política ao movimento sindical, crescimento demográfico acelerado e inflação crônica.

Posteriormente, nos anos 90, elementos como o baixo crescimento econômico, o alto desemprego e a elevada taxa de juros real parecem ter mantido a tendência à concentração da distribuição funcional e pessoal da renda. No entanto, na medida em que se moderniza a agricultura de alimentos e seus preços relativos mantêm um comportamento favorável, e levando em conta que já ocorreu a transição demográfica, tudo indica que se e quando houver uma retomada sustentada do crescimento econômico no país, com ênfase em investimentos em infra-estrutura urbana (particularmente nas cidades menores) e elevação do salário mínimo, será possível obter uma rápida redução no nível de pobreza, com impactos positivos sobre a distribuição pessoal da renda.

O problema então é como retomar o crescimento. $O$ crescimento da capacidade produtiva da economia a longo prazo depende basicamente do crescimento do investimento. $\mathrm{O}$ investimento privado, no entanto, só cresce de forma sustentada se a demanda final (consumo, construção civil, gasto público, exportações) cresce regularmente, de forma que ocupe a capacidade produtiva que está sendo criada. A expansão regular da demanda final depende em boa parte da condução da política macroeconômica.

Conforme explicado em Serrano (2001a), essas idéias simples vão contra a doutrina profundamente arraigada, válida exclusivamente numa economia centralmente planificada, de que uma queda no consumo por si só estimula o investimento privado. Na prática o único efeito direto da queda do consumo é a diminuição do nível de produto e o conseqüente aumento da capacidade produtiva ociosa que, se persistir, tende a desestimular o investimento privado.

Esse argumento diverge também de interpretações mais heterodoxas que pensam o investimento privado agregado como uma variável autônoma, que mesmo a longo prazo depende da "empolgação" dos empresários e puxa o crescimento da demanda final, em vez de ser puxada por ele. Essa visão parece desconhecer que o investimento privado cria capacidade produtiva, que se não for adequadamente utilizada, gera crescentes prejuízos, entorpecendo o processo de crescimento econômico.

$\mathrm{Na}$ prática a principal restrição objetiva a políticas macroeconômicas que levem a uma expansão ordenada da demanda final se encontra, de forma especialmente drástica no caso de países em desenvolvimento, na restrição de balança de pagamentos, pois as divisas são, em última instância, o "insumo" que é realmente escasso no processo de desenvolvimento.

Infelizmente, nem sempre a política econômica do governo está voltada para a administração racional das divisas com o objetivo de maximizar o crescimento da economia e do mercado interno. Pelo contrário, a experiência brasileira recente mostra o quão fácil e rápido é possível desperdiçar vultosos montantes de divisas e crescer muito pouco, se o governo estiver suficientemente determinado a conduzir a política econômica dessa forma, que já foi chamada de "irresponsabilidade cambial".

No estudo sobre inserção externa e o papel da taxa de crescimento das expor- 
tações no desenvolvimento brasileiro (Medeiros e Serrano, 2001a), tentamos justamente compreender melhor a relação entre a restrição de balança de pagamentos e o crescimento econômico.

É bastante comum o argumento de que, como o Brasil é uma economia dotada de vasto mercado interno, as exportações não desempenham papel tão importante em nossa economia. Além disso, pode-se apontar que, durante um dos períodos em que a economia apresentou elevadas taxas de crescimento, as exportações estagnaram (anos 50-60) e também que, num dos períodos de relativamente rápida expansão das exportações (década de 80), a taxa de crescimento da economia foi muito baixa.

É importante distinguir o papel da taxa de crescimento das exportações como componente da tendência de longo prazo da demanda final e sua função no financiamento externo do desenvolvimento econômico. As exportações podem ser mais ou menos importantes para a expansão de uma economia - de acordo com uma série de características estruturais de cada país; entretanto, seu papel no financiamento e relaxamento da restrição externa ao crescimento é absolutamente central e estratégico para todos os países, com exceção daquele que emite a moeda de circulação internacional (no momento apenas os EUA ${ }^{36}$ ). Sem dúvida, na economia brasileira as exportações não são, e dificilmente se tornarão, um componente importante da demanda final. No entanto, o crescimento das exportações tem um papel estratégico fundamental para garantir a sustentabilidade do financiamento da balança de pagamentos.

Essa reconsideração do papel central do crescimento das exportações permite também explicar o aparente paradoxo de que, na década de 80, a economia brasileira esteve sujeita a severa restrição do balanço de pagamentos, devido em grande parte ao corte e à parcial reversão dos fluxos de capital externo, enquanto na última década a economia recebeu enormes fluxos de capital (cuja "qualidade" teria melhorado nos anos mais recentes com a enorme expansão do investimento direto estrangeiro até 2000), e, no entanto, apresentou desempenho de crescimento absolutamente medíocre.

A explicação aqui estaria centrada na distinção entre o problema de liquidez externa e o problema de sustentabilidade do déficit em conta corrente e dos passivos externos.

O financiamento externo via investimento direto estrangeiro em vez de via dívida ou investimentos de portfólio, na medida em que resulte de fato num comprometimento de recursos a longo prazo no país (o que é meio duvidoso numa época em que se classificam como "investimento direto estrangeiro" dólares repatriados das Ilhas Cayman para jogar na bolsa), de fato tende a aliviar o problema da liquidez externa, problema este que está ligado aos prazos de vencimento dos passivos externos do país.

No entanto, o investimento direto estrangeiro, a não ser que, ao contrário do

\footnotetext{
${ }^{36}$ Ver Serrano (2002).
} 
que tem ocorrido no Brasil nos últimos anos, se volte para setores exportadores ou de substituição de importações, em nada ajuda a garantir a sustentabilidade a longo prazo da posição externa do país. Essa sustentabilidade depende fundamentalmente da taxa de crescimento das exportações e da variação do coeficiente de importações em relação às taxas de juros pagas nos passivos externos. Dessa forma, devido ao baixo crescimento das exportações brasileiras e ao crescimento da propensão marginal a importar, resultantes da curiosa política cambial e de abertura comercial e financeira do governo FHC, os indicadores de sustentabilidade da balança de pagamentos continuaram se deteriorando sem parar, mesmo quando os problemas de liquidez externa a curto prazo foram atenuados pelos recursos do acordo com o FMI e pela "bolha" (que parece já ter estourado) de investimento direto estrangeiro, de tal forma que atualmente o Brasil tem uma das maiores taxas de risco externo do mundo.

\section{POR QUE O COMPLEXO DE INFERIORIDADE?}

Sabemos que a abordagem que seguimos e o programa que executamos são apenas uma de muitas alternativas possíveis. Nesta conclusão, muito mais importante que explicar ou defender adicionalmente nosso programa de pesquisa é enfatizar que acreditamos fortemente que não existe absolutamente nenhuma necessidade de os economistas do desenvolvimento terem um complexo de inferioridade em relação à teoria econômica neoclássica. Também não existe nenhuma necessidade de pagar um tributo a ela, tentando desesperadamente defender de um modo neoclássico políticas que sabemos ser desejáveis por razões completamente não neoclássicas. Além disso, não precisamos realmente ficar tão agradecidos quando um eminente economista neoclássico ocasionalmente admite que alguma das coisas que os economistas do desenvolvimento dizem são, às vezes, relevantes, aqui ou ali. O colonialismo militar e político parece ter sido parcialmente reposto por um complexo de inferioridade teórico, ideológico e cultural. Porém, existe um enorme número de excelentes trabalhos críticos já prontos e sendo feitos, tanto teóricos como aplicados, no Sul e também no Norte. Se conseguirmos juntar um maior número desses trabalhos, ensiná-los e disseminá-los mais extensamente, sem passar pelas rotas (virtualmente) bloqueadas das revistas tradicionais e instituições ortodoxas do Norte, a economia do desenvolvimento, em vez de ser um sobrevivente, como uma ramificação secundária da teoria do crescimento da economia e do bem-estar neoclássico, pode se tornar novamente uma profissão socialmente útil cujo propósito, como William Petty, fundador de nossa profissão e particularmente da abordagem clássica do desenvolvimento, sabia, é ajudar os cidadãos dos vários países em desenvolvimento a alcançar "paz e abundância". 


\section{REFERÊNCIAS BIBLIOGRÁFICAS}

ASPROMOURGOS, T. (1996) On the Origins of Classic Economics. Londres: Routledge.

BASTOS, C. (2001) “Inflação e estabilização”, em Fiori, J. e Medeiros, C., eds., Polarização Mundial e Crescimento. Petrópolis: Vozes.

BIELSCHOWSKY, R. (2000) "Cinqüenta anos de pensamento na Cepal - uma resenha”. In R. Bielschowsky (org.). Cinqüenta Anos de Pensamento da Cepal, v. 1, Cepal-Record, 2000.

BLOMSTROM, M. et all (1996) "Is fixed investment the key to economic growth?", Quarterly Journal of Economics, 111 (1), 1996.

CESARATTO, S. e SERRANO, F. (2002) "As leis de rendimento nas teorias neoclássicas do crescimento econômico: uma crítica sraffiana", Ensaios FEE, 23 (2), 2002.

CESARATTO, S., SERRANO F. e STIRATI (2003) "Technical change, effective demand and employment”, Review of Political Economy, v. 15 (1), 2003.

CHAKRAVARTY, S.(1997) Writings on Development. Oxford: Oxford University Press.

CICCONE, R. (1998) "Surplus", em Kurz, H e Salvadori, N, The Elgar Companion to Classical Economics. Aldershot: Edward Elgar Publishers.

FREITAS F. e SERRANO, F. (1998) “A abordagem clássica do excedente”, mimeo, IE-UFRJ, 1998.

FURTADO, C. (1967) Teoria e Política do Desenvolvimento Econômico. São Paulo: Abril Cultural, 1983.

(1972) Análise do "Modelo” Brasileiro. Rio de Janeiro: Ed. Civilização Brasileira.

(1992) "O subsedenvolvimento revisitado", Economia e Sociedade, 1 (1), agosto, 1992.

GAREGNANI, P. (1987) “Surplus approach to economics”, in J. Eatwell, M. Milgate e P. Newman, eds, The New Palgrave Dictionary of Economics. London: Macmillan.

(2000) "Savings and investment in a system of general intertemporal equilibrium", em H. Kurz (ed.), Critical Essays on Piero Sraffa's Legacy in Economics. Cambridge: Cambridge University Press.

KALDOR, N. (1996) "The effects of interregional and international competition", em N. Kaldor, Causes of Growth and Stagnation in the World Economy. Cambridge: Cambridge University Press.

KRUGMAN, P. (1992) “Toward a counter — counterrevolution in development theory”, World Bank Economic Review Supplement, 1992.

MEDEIROS, C. (1997) “Globalização e inserção internacional diferenciada na Ásia e A. Latina”, em Tavares, M. C. e Fiori, J. L., eds., Poder e Dinheiro. Petrópolis: Vozes.

(1998) "Raízes estruturais da crise financeira asiática e o enquadramento da Coréia", mimeo, IE-UFRJ.

(1999) “China: entre os séculos XX e XXI", em Fiori, J. L. (ed.), Estado e Moedas no Desenvolvimento das Nações, Petrópolis: Vozes.

(2000) "High wage economy, fordism and sloanism: the American experience during the Golden Age”, Contributions to Political Economy, vol. 19, 2000.

(2001a) "Rivalidade estatal, instituições e desenvolvimento econômico", em Fiori, J. e Medeiros, C., eds., Polarização Mundial e Crescimento, Petrópolis: Vozes.

(2001b) "Desenvolvimento econômico, distribuição de renda e pobreza”, em Fiori, J. e Medeiros, C., eds., Polarização Mundial e Crescimento. Petrópolis: Vozes.

MEDEIROS, C. e SERRANO, F. (1999) "Padrões monetários internacionais e crescimento", em Fiori, J. L. (ed.), Estado e Moedas no Desenvolvimento das Nações. Petrópolis: Vozes.

(2001a) "Inserção externa, exportações e crescimento no Brasil", em Fiori, J. e Medeiros, C., eds., Polarização Mundial e Crescimento. Petrópolis: Vozes.

(2001b) "Capital flows to emerging markets under the floating dollar standard: a critical view based on the Brazilian experience", mimeo, IE-UFRJ.

PETRI, F. (1999) "Professor Hahn on the 'Neo-Ricardian' criticism of neoclassical economics", em Mongiovi G. e Petr F., Value, Distribution and Capital. London: Routledge.

PIVETTI, M. (1991) An Essay on Money and Distribution. London: Macmillan.

PREBISCH, R. (1949) "O desenvolvimento econômico da América Latina e alguns dos seus principais 
problemas”, em R. Bielschowsky (org.), Cinqüenta Anos de Pensamento da CEPAL, v. 1, CepalRecord, 2000.

(1981) "Capitalismo periférico, crisis y transformación". Santiago: CEPAL.

RODRIK, D. (1997) “Has globalization gone too far?”, Institute for International Economics. Washington, 1997.

SCHEFOLD, B. (2000) "Paradoxes of capital and counterintuitive changes of distribution in an intertemporal equilibrium model”, em H. Kurz (ed.), Critical Essays on Piero Sraffa's Legacy in Economics. Cambridge: Cambridge University Press.

SEN, A. (1981) Poverty and Famines: An Essay on Entitlement and Deprivation. Oxford: Clarendon Press.

SERRANO F. (2002a) “Do ouro imóvel ao dólar flexível”, Economia e Sociedade, vol. 11 (2), julho 2002.

(1993) "Review of Pivetti’s essay on money and distribution", Contributions to Political Economy, v. 13, 1993.

(1995) "Long period effective demand and the sraffian supermultiplier", Contributions to Political Economy, v. 15, 1995.

(1996) “The Sraffian Supermultiplier”, unpublished Ph.D. thesis. Cambridge University.

(1998) "Tequila ou tortilha? Notas sobre a economia brasileira nos noventa", Archetypon, v.6 (18), setembro 1998.

(2000) “A soma das poupanças determina o investimento?”, Archetypon, v. 8 (23).

(2001a) “A acumulação e o gasto improdutivo na economia do desenvolvimento", em:

Fiori, J. e Medeiros, C., eds., Polarização Mundial e Crescimento. Petrópolis: Vozes.

(2001b) "Equilíbrio neoclássico de mercado de fatores: um ponto de vista sraffiano", Ensaios FEE, 22 (1).

(2003) "Estabilidade nas abordagens clássica e neoclássica”, Economia e Sociedade, v. 12

(2), Campinas 2003.

SERRANO F. e WILLCOX D. (2000) “O modelo de dois hiatos e o supermultiplicador", Revista de Economia Contemporânea, vol. 4 (2), IE-UFRJ.

STEEDMAN, I (1987) "Foreign trade”, The New Palgrave Dictionary, Macmillan, 1987.

STIGLITZ, J. et all (1989) The Economic Role of the State. Oxford: Oxford Basil Blackwell. 